\title{
Congenital syphilis in The Netherlands: diagnosis and clinical features
}

\author{
J M BOOT, A P ORANJE, H E MENKE, R V W vAN EIJK, E STOLZ \\ From the Department of Dermatology and Venereology, Ziekenhuis Dijkzigt, Rotterdam, The Netherlands
}

SUMMARY From 1982 to 1985 the 19S IgM-Fluorescent Treponemal Antibody Absorption (19SIgM-FTA-ABS) test gave a positive result in 19 children. These 19 children plus one dizygotic twin sister were evaluated. Seventeen children were diagnosed as having congenital syphilis and treated. Clinical evidence was seen in 10 children, CSF abnormalities in seven, radiological abnormalities in eight. Of the 17 children treated, only one did not meet the Center for Disease Control (CDC) criteria of a compatible case of congenital syphilis. Of the children not diagnosed as having congenital syphilis, one child was considered to be a compatible case of congenital syphilis according to the CDC-criteria. The CDC-criteria may be a valuable aid in diagnosing congenital syphilis. Guidelines for adequate therapy are given.

Congenital syphilis occurs as an early form and a late form, the latter in children older than two years with, in some cases, stigmata. This form will not be discussed in this article.

In the early form the following clinical features may be observed: hepatosplenomegaly, generalised lymphadenopathy, skeletal lesions, haematological changes, renal lesions (more specifically glomerulonephritis), ocular lesions, lesions of the CNS and monocutaneous lesions. ${ }^{12}$ However, at birth many infants are asymptomatic. ${ }^{34}$

When congenital syphilis is suspected it is important to perform an adequate physical examination supplemented by laboratory tests and, if necessary, radiological examination of the long bones and CSF tests. The diagnosis of congenital syphilis may pose problems because pathognomonic characteristics are rarely present. ${ }^{3-5}$ Only if Treponema pallidum can be identified is the diagnosis beyond doubt. In January 1988 the CDC in Atlanta proposed a diagnostic classification of congenital syphilis (table 1). ${ }^{6}$ Dependent on serological test results, clinical features and the maternal history, a distinction is made between confirmed cases, compatible (possible, probable) cases and unlikely (improbable) cases.

Congenital syphilis is still being diagnosed in The Netherlands. During the period 1982-5 four cases were reported to the Chief Inspector of Public Health.

Address for reprints: Dr J M Boot, MD, Department of Dermatology and Venereology, Academisch Ziekenhuis, dr Molewaterplein 40, 3015 GD Rotterdam, The Netherlands.

Accepted for publication 12 June 1989

During the same period the National Institute of Public Health and Environmental Protection in Bilthoven found 19 positive 19S-IgM-FTA-ABS tests. In a detailed study these 19 cases and a twin child with a negative 19S-IgM-FTA-ABS test were further analysed. In a previous article we described the cause of the occurrence of congenital syphilis and the characteristics of parents of children with congenital

Table 1 Diagnostic classification of congenital syphilis

Confirmed case
Identification of $T$ pallidum by darkfield microscopy, fluorescent
antibody, or other specific stains in specimens from lesions,
autopsy material, placenta or umbilical cord
Compatible (formerly probable or possible) case
A reactive STS in a stillborn
A reactive STS in an infant whose mother had syphilis during
pregnancy and was not adequately treated, regardless of
symptoms in the infant
A reactive VDRL-test of cerebrospinal fluid
A reactive STS in an infant with any of the following signs:
snuffles, condylomata lata, osteitis, periostitis or osteochon-
dritis, ascites, skin and mucous membrane lesions, hepatitis,
hepatomegaly, splenomegaly, nephrosis, nephritis or hemolytic
anemia
Fourfold or greater rise in titers of nontreponemal tests (VDRL
or RPR) and a confirmed fluorescent treponemal antibody
absorption (FTA-ABS) or microhemagglutination assay for
antibody to $T$ pallidum (MHA-P) over a 3-months period
A reactive treponemal test or nontreponemal test that does not
revert to nonreactive in 6 months
Unlikely case
No reactive STS
Treponemal tests revert to nonreactive within 6 months
No symptoms in live-born infant whose mother, treated for
syphilis during pregnancy, had a fourfold or greater fall in titer
and the infant's STS is also fourfold or lower than the maternal
titer was at the time of treatment
-


syphilis. ${ }^{7}$ The present article focuses on the clinical features of these 20 children and the therapy given. In addition the problem of diagnosis and the therapy will be discussed.

\section{Patients and methods}

During the period 1982-5 the National Institute of Public Health and Environmental Protection in Bilthoven found 19 positive 19S-IgM-FTA-ABS tests in children. The names of patients and physicians in charge were elicited from the test application forms. The physicians in charge were approached and asked to complete a questionnaire about the history of the mother and her partner and about the child's medical history. If possible, the child's mother was then approached in an effort to fill possible gaps. Since this was a retrospective study, some imperfections in the data were unavoidable.

One child proved to be one of a pair of dizygotic twins. Although the other twin had a negative 19S-IgM-FTA-ABS test, there were other signs of congenital syphilis and consequently this child was included in the evaluation. Twenty children were thus available for an analysis of clinical features, serological parameters and laboratory findings. All data were processed anonymously.

\section{Results}

Five patients (cases 1-5) (all girls) were adopted children: three from Sri Lanka, one from Honduras and one from Indonesia. Therapy was instituted 2 weeks to 5 months after arrival, at the age of 12-30 weeks. The remaining 15 children ( 8 girls, 7 boys) were born in The Netherlands. Four of them were Surinamese, three Cape Verdian, two Turkish, one Moroccan, one German and four Dutch. The start of therapy ranged from three days after birth to three months after birth.

Ten of the 20 children showed clinical evidence of congenital syphilis. Hepatosplenomegaly was observed in six (cases 10,14, 15, 16, 18, 19), desquamation of the fingers or hands in four (cases 10, 14, 18,20 ), purulent rhinitis in two (cases 2,20 ), depigmentation in two (cases 2,15 ), lymphadenopathy in two (cases 14,15), signs of osteomyelitis in two cases (cases 16, 17), while exanthema was seen in one case (case 19), and perianal ulceration in another (case 4).

CSF tests were performed in 17 cases. A normal cell count $^{8}$ (WBC 32/1) and a normal protein concentration $^{8}(1170 \mathrm{mg} / \mathrm{dl})$ was found in 10 cases, with in three cases a positive TPHA in the CSF (cases $1,9,20$ ). Serum and CSF TPHA titres were not compared. CSF abnormalities were found in seven cases. In one the cell count was increased and positive serological reactions were seen (case 10); however, the erythrocyte count was also increased and so there might have been blood ad-mixture. In one case the CSF showed a weakpositive 19S-IgM-FTA-ABS test (case 17). Five CSF specimens showed a positive VDRL, the titre ranging from 1:2 to $1: 4$ (cases 11, 12, 15, 18, 19). Corresponding titres in serum ranged from 1:8 to 1:128. In two cases of these five cases the erythrocyte count in the CSF was also increased (cases 18, 19). In five cases the CSF findings were negative but there were clinical features of congenital syphilis (cases $2,4,14,16,20$ ). In two cases there were CSF changes without any clinical features of congenital syphilis (cases 11, 12). In 13 cases no radiological examination was performed. In five cases there were no radiological changes. Eight cases did show radiological changes, ranging from a slight periosteal reaction via decalcification of the long bones to features consistent with osteomyelitis.

General laboratory tests revealed anaemia in eight cases, an increased ESR in five, liver function disorders in three, thrombocytopenia in two, and leucocytosis in two cases. Table 2 presents an overview of the clinical features and the diagnostic efforts made in all patients.

Congenital syphilis was diagnosed and therapy was instituted in 17 children. In three children the diagnosis was not made (cases $6,7,8$, table 2). These three children showed a single positive 19S-IgM-FTA-ABS test, one in umbilical cord blood, one at the age of 4 weeks, and one during the seventh week of life. Since there were no clinical signs suggestive of congenital syphilis, a serological follow-up was carried out. One mother had not been treated in spite of positive syphilis serology (VDRL-, TPHA + and FTAABS +) during pregnancy (case 8). The child was submitted to a serological follow-up. At the age of 9 months all serological parameters were negative. In the second case (case 6), too, all serological parameters were negative at the age of 9 months. In the third case (case 7) the mother had had a 10-day penicillin course (i.m.) during the second trimester of pregnancy. Unfortunately the follow-up on the child did not continue beyond the third month of life. At that time a positive TPHA and a positive FTA-ABS test remained.

In 10 of the 17 children treated, the diagnosis had been made because of clinical features, sometimes in combination with CSF changes, abnormal radiological findings, or abnormal laboratory findings (cases 2, 4, 10, 14-20, table 2). In two cases congenital syphilis was diagnosed because radiological examination revealed lesions of the long bones, in combination with a fourfold increase in VDRL titre (cases 1,3 , table 2). In two cases the diagnosis was established by a positive VDRL in the CSF in combination with the fact that the mother had had a positive serology during 
Table 2 Clinical signs and results of CSF-examination, radiological examination and other laboratory tests

\begin{tabular}{|c|c|c|c|c|c|c|c|}
\hline \multirow[b]{2}{*}{ Patient } & \multirow{2}{*}{$\begin{array}{l}\text { Clinical } \\
\text { signs }\end{array}$} & \multicolumn{3}{|c|}{ First known STS } & \multirow{2}{*}{$\begin{array}{l}C S F \\
\text { examination }\end{array}$} & \multirow{2}{*}{$\begin{array}{l}\text { Radiological } \\
\text { examination }\end{array}$} & \multirow{2}{*}{$\begin{array}{l}\text { Other } \\
\text { laboratory } \\
\text { tests }\end{array}$} \\
\hline & & $T P H A$ & $F T A-A B S$ & $V D R L$ & & & \\
\hline $\begin{array}{r}1 \\
2 \\
3 \\
4 \\
5 \\
6 \\
7 \\
8 \\
9 \\
10 \\
11 \\
12 \\
13 \\
14\end{array}$ & 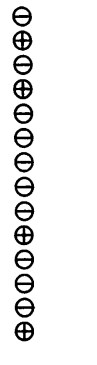 & $\begin{array}{l}\oplus_{\oplus}^{\oplus} \\
\oplus_{\oplus}^{\oplus} \\
\oplus_{\oplus}^{\oplus} \\
\oplus_{\oplus}^{\oplus} \\
\oplus_{\oplus}^{\oplus} \\
\oplus_{\oplus}^{\oplus}\end{array}$ & $\begin{array}{l}\oplus_{\oplus}^{\oplus} \\
\oplus_{\oplus}^{\oplus} \\
\oplus_{\oplus}^{\oplus} \\
\oplus_{\oplus}^{\oplus} \\
\oplus_{\oplus}^{\oplus} \\
\oplus_{\oplus}\end{array}$ & $\begin{array}{l}1: 4 \\
\oplus \\
1: 16 \\
1: 64 \\
1: 32 \\
\ominus \\
\ominus \\
\ominus \\
1: 8 \\
1: 128 \\
\ominus \\
\ominus \\
1: 1 \\
1: 128\end{array}$ & $\begin{array}{l}\text { normal } \\
\text { normal } \\
\text { normal } \\
\text { normal } \\
\text { normal } \\
\text { not done } \\
\text { not done } \\
\text { not done } \\
\text { normal } \\
\text { cell count } \uparrow \\
\text { VDRL } \oplus \\
\text { VDRL } \oplus \\
\text { normal } \\
\text { normal }\end{array}$ & $\begin{array}{l}\text { abnormal } \\
\text { abnormal } \\
\text { abnormal } \\
\text { abnormal } \\
\text { normal } \\
\text { not done } \\
\text { not done } \\
\text { not done } \\
\text { not done } \\
\text { abnormal } \\
\text { not done } \\
\text { not done } \\
\text { normal } \\
\text { normal }\end{array}$ & $\begin{array}{l}\text { normal } \\
\text { normal } \\
\text { anaemia, liver dysfunction } \\
\text { liver dysfunction } \\
\text { ESR } \uparrow \text {, anaemia } \\
\text { not done } \\
\text { normal } \\
\text { not done } \\
\text { normal } \\
\text { normal } \\
\text { not known } \\
\text { not known } \\
\text { normal } \\
\text { ESR } \uparrow \text {, anaemia, leucocytosis, } \\
\text { trombopenia }\end{array}$ \\
\hline 15 & $\oplus$ & $\oplus$ & $\oplus$ & $1: 64$ & VDRL $\oplus$ & abnormal & $\begin{array}{l}\text { ESR } \uparrow \text {, anaemia, liver } \\
\text { dysfunction }\end{array}$ \\
\hline $\begin{array}{l}16 \\
17 \\
18 \\
19 \\
20\end{array}$ & $\bigoplus_{\oplus}^{\oplus}$ & $\stackrel{\oplus}{\oplus}$ & $\stackrel{\oplus}{\oplus}$ & $\begin{array}{l}1: 64 \\
1: 9 \\
1: 128 \\
1: 16 \\
1: 8\end{array}$ & $\begin{array}{l}\text { normal } \\
\text { IgM weakly } \\
\text { VDRL } \oplus \\
\text { VDRL } \oplus \\
\text { normal }\end{array}$ & $\begin{array}{l}\text { abnormal } \\
\text { abnormal } \\
\text { not done } \\
\text { normal } \\
\text { normal }\end{array}$ & $\begin{array}{l}\text { ESR } \uparrow \text {, anaemia, leucocytosis } \\
\text { ESR } \uparrow \text {, anaemia } \\
\text { anaemia } \\
\text { anaemia, trombopenia } \\
\text { normal }\end{array}$ \\
\hline
\end{tabular}

pregnancy and had never been treated before (cases 11 , 12 , table 2). In one case the syphilis serology was determined routinely after admission in view of heroin withdrawal symptoms. The mother was a heroinaddicted prostitute who in the 29th week of pregnancy had shown a negative syphilis serology that had turned positive after giving birth to the child. The child showed a fourfold rise in VDRL titre in a period of four weeks, and because of this treatment was started (case 13, table 2). Another child was treated in view of a high VDRL titre (1:32) at the age of 30 weeks, with a positive TPHA, FTA-ABS and 19S-IgM-FTA-ABS test (case 5, table 2). In addition there was an increased ESR and anaemia. This was an adopted child from Honduras, where she had been treated with benzathine penicillin $2 \times 300000 \mathrm{U}$, because of bone defects. In view of persistently high titres it was considered safer to institute therapy. One child (case 9) was treated only in view of a positive 19S-IgM-FTAABS test, VDRL 1:8 and a positive TPHA and FTAABS test during the first week of life, with no other signs of congenital syphilis. The mother had been treated during the 12th week of pregnancy, with repeated treatment during the 24th week in view of a persistent VDRL titre of $1: 8$.

Treatment of the 17 children varied considerably. For patients with abnormal CSF findings therapy ranged from i.v. administration of $80000 \mathrm{U}$ penicillin per day for 14 days to $600000 \mathrm{U} /$ day for 21 days, and from i.m. administration of $150000-220000 \mathrm{U}$ penicillin per day for 10 days to $175000 \mathrm{U} /$ day for 21 days. For patients without CSF changes therapy ranged from a single i.m. dose of $250000 \mathrm{U}$ benzathim penicillin (Penidural D/F) to i.m. administration of
$600000 \mathrm{U}$ procaine penicillin (Bicillin) for 10 days, and from $400000 \mathrm{U}$ benzyl penicillin i.m. for 14 days to $200000 \mathrm{U}$ procaine penicillin (Depocillin) for 21 days. Three children received intravenous therapy in doses of $50000 \mathrm{U} / \mathrm{kg} /$ day to $320000 \mathrm{U} /$ day for periods ranging from 10 to 14 days.

\section{-Discussion}

A diagnosis of congenital syphilis depends on the mother's history, clinical features in the child, laboratory (especially CSF) findings, radiological findings and serological parameters. Of the 20 children suspected of congenital syphilis, only 13 were submitted to physical examination as well as radiological examination, laboratory studies and CSF tests.

A diagnosis of congenital syphilis must be considered if the clinical features are consistent with it or if the mother's history indicates that the child may have been infected. The relevance of precise data on the mother's history has been discussed in a previous article. $^{\text {? }}$

An evaluation of the CDC criteria for diagnosis of congenital syphilis with regard to the children in this study reveals that one child (case 7, table 2) did not develop congenital syphilis although the criteria indicated a compatible case. The mother had had untreated syphilis during pregnancy, but the child showed none of the clinical features of congenital syphilis and the serology was entirely negative after - nine months.

Of the 17 children treated, only one did not meet the criteria of acompatible case of congenital syphilis. The mother had been treated during pregnancy, and the 
child was treated in view of a positive 19S-IgM-FTAABS test during the first week of life in combination with a positive TPHA, a positive FTA-ABS test and a VDRL 1:8. No other criteria were fulfilled (case 9, table 2).

To diagnose neurosyphilis in children with congenital syphilis an examination of CSF has to be done. The number of lymphocytes, and erythrocytes, and the protein content has to be measured. Also serological tests have to be performed.

Normal values differ in accordance with the age of the child': in preterm infants the CSF cell count and protein content tends to be higher than in term neonates.

It is suggested that in younger children the bloodbrain barrier functions differently from that in older children. ${ }^{910} \mathrm{CSF}$ abnormalities in children with congenital syphilis are found in $25 \%{ }^{8}$ to $80 \%$ of the cases. ${ }^{3}$ We found in $50 \%(5 / 10)$ CSF abnormalities: once a raised cell count, once a weakly positive 19S-IgMFTA-ABS and three times a positive VDRL. We also found a positive VDRL in CSF in two children with no other clinical signs of congenital syphilis. Other studies have indicated no CSF abnormalities in children without clinical signs of congenital syphilis. ${ }^{8}$

The importance of a positive VDRL in CSF is still debated. ${ }^{3}$ The CDC regards in its diagnostic classification of congenital syphilis a positive VDRL in the CSF as indicative of a compatible case of congenital syphilis. A positive VDRL was found in five cases in this study. However, it should be pointed out that this can be caused by blood admixture or passive transfusion due to a poorly functioning blood brain barrier. An ITPA-index ${ }^{11}$ or an TPHA index ${ }^{12}$ as used in diagnosing asymptomatic neurosyphilis in adults might also be useful for children. Further investigation seems desirable.

The CDC criterion of a positive serology six months after birth as indicative of congenital syphilis may be too restrictive; one child in this study showed a positive FTA-ABS test at the age of 25 weeks, while at the age of 9 months the serology was entirely negative.

Not only a fourfold rise in VDRL titre is an important serological parameter. In The Netherlands the 19S-IgM-FTA-ABS test is likewise regarded as a valuable aid in diagnosing congenital syphilis. However, it should be borne in mind that some time may elapse before the production of IgM antibodies properly starts. One adopted child was screened at the age of 4 weeks. The 19S-IgM-FTA-ABS test was negative, while only the TPHA and FTA-ABS test were positive. At the age of 11 weeks the 19S-IgMFTA-ABS was still negative, but at the age of 21 weeks it proved positive. A negative IgM test, therefore, does not exclude an infection with certainty: it may turn positive at a later stage. On the other hand, a positive 19S-IgM-FTA-ABS test need not necessarily be con- clusive of a syphilitic infection. Particularly during the first two weeks of life such a positive test may be attributable to materno-foetal transmission. ${ }^{4}$ The findings of this study corroborate the value of radiological examination: radiological lesions were detected in eight of the 13 children so examined.

As to therapy, we consider it advisable to follow the guidelines issued by the Health Council. ${ }^{13}$ Symptomatic neonates or asymptomatic neonates with CSF changes should be given aqueous crystalline penicillin G solutions at a dosage of $50000 \mathrm{U} / \mathrm{kg}$ i.m. or i.v. divided into two doses per day for at least 10 days, or aqueous procaine penicillin solutions at a dosage of $50000 \mathrm{U} / \mathrm{kg} /$ day i.m. for at least 10 days. Asymptomatic neonates with normal CSF findings may be given $50000 \mathrm{U}$ penicillin $\mathrm{G}$ benzathine i.m. in a single dose. The $\mathrm{CDC}^{14}$ recommends for asymptomatic neonates the same therapy as for symptomatic ones. For asymptomatic infants whose mothers were adequately treated during pregnancy but whose follow-up cannot be ensured they recommend 50000 $\mathrm{U} / \mathrm{kg}$ benzathine penicillin i.m. in a single dose. Uniformity of diagnostic approach, therapy and follow-up facilitate comparative studies and should therefore be encouraged.

\section{References}

1 Holmes KK, Mardh P-A, Sparling PF, Wiesner PJ, eds. Sexually Transmitted Diseases. New York: McGraw-Hill, 1984:358-63.

2 Remington JS, Klein JO. In: Infectious diseases of the fetus and newborn infant. 2nd ed. Philadelphia: WB Saunders Company, 1983:346-50.

3 Mascola L, Pelosi R, Blount JH. Congenital syphilis revisited. Am $J$ Dis Child 1985;139:575-80.

4 Pichering LK. Diagnosis and therapy of patients with congenital and primary syphilis. Pediatric Infectious Disease 1985;4: 602-5.

5 Srinivasan G, Ramamunthy RS, Bharathi A. Congenital syphilis: a diagnostic and therapeutic dilemma. Ped Infect Dis 1983;6: 436-41.

6 CDC-MMWR Jan 15, 1988/Vol 37. No S-1. "Guidelines for the prevention and control of congenital syphilis." Atlanta, Georgia.

7 Boot JM, Menke HE, Eyk RVW van, et al. Congenital syphilis in The Netherlands: cause and parental characteristics. Genitourin Med 1988;64:298-302.

8 Sarff LD, Platt LH, McCracken GN Jr. Cerebrospinal fluid evaluation in neonates: Comparison of high-risk infants with and without meningitis: $J$ Pediatr 1976;88:473-7.

9 Thorley JD, Holmes KK, Kaplan JM, et al. Passive transfer of antibodies of maternal origin from blood and cerebrospinal fluid in infants. Lancet 1975; i:651-3.

10 McCracken GN, Kaplan MD. Penicillin treatment for congenital syphilis. A critical reappraisal. JAMA 1974;228:855-8.

11 Müller F, Moskophidis M. Estimation of the local production of antibodies to Treponema pallidum in the central nervous system of patients with neurosyphilis. Br J Vener Dis 1983;59:80-4.

12 Luger A, Schmidt BL, Steyrer K. Neurosyphilis, a retrospective evaluation of 22 cases. WHO/INT NDT/80.361, Geneva: WHO, 1980.

13 Advies inzake Seksueel Overdraagbare Aandoeningen, 's-Gravenhage 26 juni 1986, blz. 176-77. (Guidelines for Sexually Transmitted Diseases.) Atlanta, Georgia.

14 CDC-MMWR, 1985;34:97S-99S. 